\title{
Unintentional injuries in the home environment: home safety
}

\author{
Carlos E. N. Paes, ${ }^{1}$ Vera L. V. Gaspar ${ }^{2}$
}

\begin{abstract}
Objective: To review the characteristics of unintentional injuries and their impact on children and adolescents.

Sources of data: Articles published between 2000 and 2005 in the MEDLINE, EBSCO, Proquest, SciELO, BVS and Google Scholar databases were selected. The authors used the keywords unintentional injuries, injuries, safe home, burns, falls, drowning, scorpions, snakes, poisoning, child, adolescent, mortality, injury control, and hospitalization. Some articles were evaluated based on the selected publications.

Summary of the findings: Unintentional injuries in the world and in Brazil are analyzed, and so are the behaviors currently adopted for injury prevention and control. The impact on mortality, on physical damage, and the economic burden of injuries are evaluated. Special emphasis is placed on home environment, approaching the effects of child development, social disparities and contextualization of home environment on children's world and vulnerabilities. The main types of events that cause physical damage to the child and adolescent in the home environment are described.

Conclusion: The prevention of injuries in the home environment is possible. In this case, health professionals have the challenge to reduce the consequences of unintentional injuries on the morbidity and mortality of children and young people in Brazil and in the whole world.
\end{abstract}

J Pediatr (Rio J). 2005;81(5 Suppl):S146-S154: Safety, accident prevention, injuries, home accidents, home safety, injury control.

\section{Introduction}

In Brazil, unintentional injuries accounted for 755,826 hospital admissions in 2004, of which 216,377 involved individuals aged up to 19 years old. ${ }^{1}$ In 2002, 22,373 children and adolescents died from external causes in Brazil. ${ }^{2}$ Except for perinatal diseases, this group includes the largest number of deaths among Brazilian individuals aged 0 to 19 years.

In 2001, unintentional injuries were the major cause of death among people aged 1 to 34 years old, and the fifth major cause of death in all age groups in the USA. ${ }^{3}$ In Canada, over two million injuries occur per year, resulting in 125,000 hospital admissions and more than 7,700 deaths. ${ }^{4}$ In China, it has been estimated that

1. Pediatrician. Scientific Department of Child and Adolescent Security, Brazilian Society of Pediatrics.

2. MD. Scientific Department of Child and Adolescent Security, Brazilian Society of Pediatrics.

Suggested citation: Paes CE, Gaspar VL. Unintentional injuries in the home environment: home safety. J Pediatr (Rio J). 2005;81(5 Suppl):S146S154.
800,000 deaths from injuries occur every year, with 50 million nonfatal injuries producing physical disabilities of different severity levels in 2.3 million people. ${ }^{5}$ Even in Europe, these figures vary substantially: whereas western European countries manage to reduce the impact of injuries on morbidity and mortality, eastern European countries, especially those of the Community of Independent States (former USSR) suffer the consequences of living conditions on health, mainly external causes. ${ }^{6}$ Children and adolescents up to 19 years of age have a mortality of $1.4 / 10,000$ inhabitants in the population of the first group, of $2.4 / 10,000$ in the second group and of $6.6 / 10,000$ children and adolescents in the third group. ${ }^{6}$

The major causes of fatal and nonfatal injuries vary considerably in the USA. Although nonfatal injuries are the main cause of death among individuals aged 0 to 14 years, they occur much less frequently. Due to the easier access to mortality data and to their uniformity, these events are more widely published than nonfatal ones. A 
study that compared fatal and nonfatal injuries among young people revealed a frequency of 1,000 emergency cases for every death. ${ }^{7}$

One of the greatest impacts of these injuries is on economic development and production capacity of a country. These impacts involve medical expenses (hospital admissions, medications), non-medical expenses (absence from work, labor force replacement), costs with lost opportunities (administrative health costs, hiring of third parties in the health sector) and other intangibles (changes in productivity rates, satisfaction with the job, etc.) ${ }^{4}$ In Australia, a cost of AU\$13,304,824.00 was estimated between 1995 and $1996 . .^{8}$ In Canada, there is an estimated annual cost of 8.7 billion dollars with temporary or permanent production losses caused by unintentional injuries. ${ }^{4}$ In that country, it is estimated that 630 million dollars a year are spent with childhood falls alone. 4

In the USA, medical expenses with injuries remained relatively unchanged between 1985 and 2000, being estimated at US $\$ 117$ billions, ${ }^{9}$ and accounting for $10.3 \%$ of the total medical expenses. The total costs including direct and indirect expenses amounted to US\$ 1.7 trillion in 2000 . In 2002, there were 106,742 deaths from injuries, 5.6 million hospital admissions ${ }^{10}$ and 40.2 million emergency treatments in the following year. ${ }^{11}$ In countries with a lower development than northern hemisphere countries, such as Vietnam, $90 \%$ of the expenses with the treatment of injuries must be paid by the victim and his/her family, being equivalent to seven months of work. ${ }^{12}$ In that same time period, unintentional injuries were the major cause of potential life years lost before the age of 65 , totaling two million life years lost every year. ${ }^{13}$ Despite the certainty that household accidents account for a significant share of unintentional injuries, their prevalence is only inferred in Brazil, since reliable nationwide studies on this issue are nonexistent. Unlike other countries, Brazil does not have an information system able to identify how many emergency cases are related to household events, a procedure that has been used for decades in some other countries. ${ }^{14-16}$

\section{Some characteristics of the injuries}

The causes of fatal and nonfatal injuries are totally different. Although falls are the tenth cause of death from unintentional injury, it is the main cause of treatment in U.S. emergency rooms. In 2001 , there were $2,413,888$ emergency cases involving unintentional injuries. There was one death in every 19,007 falls treated in emergency rooms. Likewise, despite $1,757,870$ cases with different traumas, there was one death in every 15,420 events. On the other hand, one death occurred in every six drownings or near-drownings, showing that it is the third major cause of death in this age group, even though it is the 15 th cause of injury in emergency rooms. ${ }^{17}$

The characteristics of the injuries vary according to age, and are predominantly more frequent among males; however, it is not possible to determine the specific differences of household injuries according to sex. ${ }^{18}$

\section{Characteristics of household injuries}

As home is the place where children spend most of their time in, this is where most injuries occur, especially among younger children. ${ }^{19}$

Waisman et al. assessed patients aged 0 to 14 years and found out that $51.9 \%$ of injuries took place at home and that the younger the child, the higher the frequency of household injuries. 20

Falls are the major cause of hospital admission in the pediatric population, also in Brazil. In 2004, falls were the main reason for hospital admission in all age groups (up to 19 years old), and $73.01 \%$ of the admissions were due to external causes. ${ }^{21}$

In Canada, $65.6 \%$ of falls involving individuals up to 19 years of age occur at home and need hospital treatment; this rate increases to $92.3 \%$ among infants (up to one year of life). ${ }^{22}$ Nevertheless, only $6 \%$ of hospital treatments require admission.

From 1992 to 1999 , there was an average of 146,970 deaths from injuries in the USA, and $20 \%$ of those injuries took place at home. Among children and adolescents aged up to 14 years, there were on average 2,096 deaths from household unintentional injuries. There was a 1.61:1 male/female ratio, and these injuries were more frequent in individuals aged 9 to 14 years $(2.1: 1){ }^{23}$ Burns and electric shocks, inhalation and choking, and drowning are the main causes of household unintentional injuries among individuals aged less than 15 years in the USA. In the first year of life, choking and aspiration are the major causes of death; thereafter, burns and electric shock are the main killers. In all age groups, from 0 to 11 years, falls accounted for the highest rate of emergency care per every 100,000 inhabitants, between July 2000 and June 2001, especially between the 12th month of life and the fifth year of life. Multiple traumas occur in all age groups, but their frequency increases after the 11 th year of life.

The study by Phelan et al., which included patients aged 0 to 19 years, showed that household unintentional injuries had an annual rate of 4.01 million cases treated in emergency rooms in the USA, resulting in $27 \%$ of all admissions due to unintentional injuries, in the same age group; there was a male predominance. 24

However, treatment of household injuries is not restricted to emergency rooms. Hambidge et al. found that $79 \%$ of the cases of injuries among children aged up to five years, treated in primary care settings, occurred at home. ${ }^{25}$ Gaspar et al. assessed patients aged 0 to 19 years, who had been admitted due to external causes of morbidity and mortality, and discovered that $39.1 \%$ of the injuries had taken place in the household. 26

\section{Vulnerable populations}

Ecological studies found a negative correlation between the GDP of 51 countries and unintentional injuries involving children aged between 5 and 14 years, but this correlation was not observed in all social strata. ${ }^{27}$ European studies 
have pointed out growing social discrepancy as the cause for the increase in the number of injuries and for their impact on the quality of life in Europe. ${ }^{28}$

Vulnerable social groups and individuals are at higher risk for unintentional injuries. These groups include socially excluded populations and handicapped individuals. ${ }^{29}$ The situations are varied and may include aspects related to education, wage, housing conditions, access to health services, or ethnics. They can also be related to circumstantial situations, such as unemployment, nonexistence of a family support network or a large number of children. ${ }^{30-32}$

The reduction of this vulnerability and of inequalities brings about a better quality of life in childhood and reduction of deaths from unintentional injuries. However, in populations with few inequalities and in those with strong social discrepancies, changes occur at a slower pace. ${ }^{33}$ The influence of inequality, however, is stronger over intentional injuries. ${ }^{34}$ Nevertheless, in a study conducted with preschool children in Pelotas, state of Rio Grande do Sul, in southern Brazil, family income, parental education and maternal work were not correlated with the occurrence of injuries. ${ }^{35}$ Another aspect to be considered is the adoption of safe behaviors, which may explain the smaller occurrence of injuries in some families. ${ }^{36}$

\section{Intentional injuries: child and adolescent abuse}

The study by Agran et al. with children aged 0 to 3 years showed that the highest frequency of aggressive events occurred in the first months of life, i.e., among infants aged between 0 and 5 months of life. ${ }^{37}$ Rimsza et al. also observed the early occurrence of aggressive events when analyzing the data about the deaths of 67 children and adolescents, aged 0 to 17 years, which resulted from violence. Of this total, 25 died before turning one year old and the shaken baby syndrome was the most frequent type of aggressive event. ${ }^{38}$

Head trauma, as a result of child abuse, should be diagnosed as early as possible, allowing for proper intervention, in order to reduce morbidity and mortality related to this type of injury. ${ }^{39}$

Acts of violence are usually committed by the father, mother's boyfriend or partner, or by the mother. ${ }^{38}$ The study by Dias et al. showed that educational programs for parents, which should start in the maternity ward, significantly reduce the incidence of head trauma caused by child abuse in individuals younger than three years. ${ }^{40}$

\section{The most frequent injuries}

Falls are the most frequent types of household injuries. ${ }^{24}$ Burns often occur in the kitchen. ${ }^{41-43}$ In the age group of 1 to 3 years, most drownings occur in residential swimming pools. ${ }^{44}$ In the study by Rangel et al., almost all poisoning cases occurred at home, 45 as well as the scorpion envenomations investigated by Amorim et al. 46

By analyzing the deaths of 1,110 patients aged 0 to 18 years, investigated at the department of legal medicine,
Çekin et al. observed that household injuries accounted for $24.3 \%$ of the total number of deaths, which resulted mainly from falls from roofs and porches, burns, electrocution, drowning and poisonings. There was a male predominance in this group of patients as well. 47

\section{Falls}

According to the World Health Organization, falls ranked as the world's fifth cause of disease among children aged 5 to 14 years in $2000 .{ }^{48}$ In Brazil, according to Datasus, 443 children and adolescents aged 0 to 19 years died from falls in $2002 .^{2}$

Among children, falls are the most frequent type of unintentional injury. ${ }^{49}$ Their extent are highlighted in the study by Phelan et al., which revealed that falls are the predominant type of household injury among individuals aged 0 to 19 years, accounting for $38 \%$ of emergency treatments in the USA. ${ }^{24}$ The study by Agran et al., in 2003, with children aged between 0 and 3 years, showed that falls were the major mechanism of trauma; ${ }^{37}$ Sandi \& Salas also observed this predominance. ${ }^{50}$ Studies demonstrated a male predominance. $41,51,52$

In the first year of life, falls are the most frequent type of injury. From 0 to 2 months of life, people carelessly let children fall; and between 3 and 11 months of life, falls from pieces of furniture are common. ${ }^{53}$

With regard to falls of under-one-year-olds, Dedoukou et al. showed that $37.2 \%$ of infants fell from a piece of furniture and that $36.2 \%$ fell from child care products, especially from the baby walker and baby carriage. The authors urge great caution with the changing table as it is responsible for falls associated with the highest frequency of hospital admissions. ${ }^{51}$

Falls from windows are predominant among under-fiveyear-old male patients, possibly because these children are constantly driven by impulse, and lack the ability to recognize danger in a concrete manner. ${ }^{52}$

As for the types of falls, the study by Gaspar showed that $34.2 \%$ occurred on the same level; followed by falls from buildings or other structures (13.8\%); from stairs $(11.7 \%)$; other falls from one level to another $(9.1 \%)$; off the bed $(8.6 \%)$; from trees $(6.5 \%)$; from other type of furniture $(5.6 \%)$; in addition to falls from the lap, from chairs and other types $(10.5 \%)$. The ages of patients who fell off the bed ranged from 0 to 5 years, and $65 \%$ was younger than one year. ${ }^{41}$

Macgregor noted that falls off the bed, cradle or bunk bed often occur in sleeping children younger than six years; in her study, $16 \%$ of the patients who fell off the bed necessitated to be hospitalized and remained under observation in the emergency room or was submitted to other procedures. The author recommends that children younger than six years should not be allowed to sleep on the top bunk bed, since a fall in this case may be remarkably severe. ${ }^{54}$

To prevent falls, the following measures, based on the study by Britton, ${ }^{49}$ are recommended: 
1) Prevention for when children are walking or running:

a) Keep toys and other objects off the floor.

b) Rugs must be fixed with double-faced Scotch tape or lined with anti-skid rubber.

c) If any liquid substance is spilt on the floor, it must be wiped off right away.

2) For prevention of falls from stairs:

a) Never leave objects on the stairs.

b) Install a safety gate at the top and bottom of the stairs, if there are young children in the household.

c) The use of baby walkers is contraindicated.

3) Prevention of falls from the bed:

a) Avoid playing risky games on the bed.

b) Children younger than six years should never be allowed to sleep on the top bunk bed.

4) Prevention of falls from windows and porches:

a) Install safety devices on the windows.

b) Never place a cradle or any other piece of furniture next to the window.

c) Never allow children to play on fire escape ladders, roofs and porches.

Dedoukou et al. point out that young children need to be supervised by careful adults, who can properly choose the pieces of equipment and make the necessary changes for the safety of infants. ${ }^{51}$

\section{Burns}

Burns cause pain and suffering in children, leave sequelae and compromise their psyche. 42 Those with severe burns have a slow recovery and may have abnormal bone growth and functional loss. ${ }^{55}$ Families are affected by their children's suffering and burdened with financial costs. ${ }^{42}$ Hall et al. interviewed parents of hospitalized burn victims and found out that three months after the event a significant share $(47 \%)$ of the children had remarkable symptoms of posttraumatic stress. 56

In Brazil, in 2002, according to Datasus, 266 children and adolescents aged 0 to 19 years died from exposure to smoke, fire and flames. ${ }^{2}$

Burns are a type of injury that predominantly occurs at home, especially in the kitchen, $41-43$ and which affects mainly children aged between 1 and 4 years. ${ }^{41}$

The study carried out by Drago with burn victims aged 0 to 5 years revealed that $33.9 \%$ of the burns had occurred in one-year-olds and $20 \%$ in two-year-olds, totaling $53.9 \%$ of the burns among children between one and two years old. 57

Scald burns are the most common type of burn injury, and are caused mainly by beverages, foods, oil and other hot liquids which, when spilt, cause injuries to the trunk, shoulder, arm and forearm; hip, thigh and leg and also to the head and neck. ${ }^{41}$
The following measures are recommended for the prevention of burns, according to Mukerji et al.: 42

1. Children should not be allowed access to electric appliances, matches and lighters; only adults should use them.

2. Young children should not be allowed in the kitchen; if that is necessary, they have to be constantly supervised.

3. Never drink or carry hot liquids while holding or carrying a child.

4. Cooking and carrying hot liquids should be done by adults, never by children.

5. In the bathroom, hot water, either in the bucket or in the bathtub, poses a risk for children who, therefore, should never be left unattended. The temperature of the water should be checked before the bath.

6. At the table, the foods should be placed at the center, and no tablecloth should be used.

7. Children should not have access to cords, electric lines, sockets and switches. All outlets should be covered with socket protectors.

Drago recommends constant surveillance of young children, so as to protect them from burns. Parents should be provided with information about the different stages of development of their children, so that they can follow their growth and recognize gender-specific behaviors, thus being better prepared to assess the risks of burns and to take safety measures. 57

The specific characteristics of the household environment may contribute to the occurrence of injuries, such as the presence of protection bars or the improper storage of toxic products. Environmental characteristics may also contribute to the severity of injuries. The flammability of certain pieces of furniture or of the house structure can cause a fire to spread rapidly. 58

\section{Poisonings}

The study by Rangel et al. with 609 poisoning patients aged 0 to 14 years showed that $98.7 \%$ of the cases took place at home; $53 \%$ involved children between 0 and 4 years (unintentional poisonings), and in this group, $58.2 \%$ of patients were boys. According to the authors, the large number of poisonings among young children is due to their curiosity about the surrounding environment, which makes them taste different substances. Patients between 10 and 14 years accounted for $32.6 \%$ of the poisonings, and differently from the previous group, $67.3 \%$ of the poisonings were intentional, with a female predominance (78.3\%). 45

Lam assessed 1,696 poisoning patients and noted that hospitalization rates were higher among male children aged between 0 and 9 years, whereas there was a female predominance among those aged between 10 and 19 years. Most poisonings were caused by painkillers and antipyretics (43\%) and psychotropic drugs (34.8\%). Paracetamol was responsible for the largest number of poisonings, whereas antidepressants and benzodiazepines were the most predominant psychotropic drugs that caused poisoning. 59 
The behavior of poisoning rates was evaluated in the study conducted by Agran et al. The authors showed that the rate of unintentional poisoning amounted to 83 poisonings per 100,000 inhabitants in one-year-olds; at four years of age, this rate decreased to 14 per 100,000 inhabitants. Inversely, the same study showed an increase in selfinflicted poisonings among adolescents; at 11 years of age, there were four poisonings in every 100,000 inhabitants, rapidly increasing to 101 per 100,000 inhabitants at 16 years of age. This increase in the rate of self-inflicted poisonings, which clearly occurs in this age group, indicates the necessity to identify those adolescents at risk. ${ }^{60}$

In order to prevent poisonings, it is recommended that guidance on preventive measures be initiated during prenatal appointments and continue during well-child visits. ${ }^{61}$ The following measures are indicated, based on the AAP recommendations: 61

1. Medications that are not being used or that are no longer necessary should be safely disposed of.

2. Medicine bottles must be closed immediately after use with a childproof cap.

3. Never tell a child that medicines taste sweet.

4. Toxic substances and medications must be kept in their original package, i.e., they should never be transferred to another flask, bottle, etc.

5. Products that may possibly cause poisoning must be kept beyond children's reach.

6. Health professionals who care for children should instruct parents and surrogates on how to prevent poisonings.

7. The syrup of ipecac is not recommended for routine domestic use.

8. If one suspects of the intake of toxic substances by the child, the first thing parents or surrogates must do is call a poison control center. Therefore, the poison control center number must always be at hand, by the phone, for instance. 61

\section{Drowning}

According to Datasus, 1,001 children between 0 and 9 died in Brazil in 2002 due to drowning or unintentional submersion. ${ }^{2}$

Among infants (younger than one year old), drownings took place in swimming pools, bathtubs and small (portable) pools and occurred due to carelessness of parents or surrogates. Residential swimming pools pose a great drowning risk for children aged between 1 and 3 years; it has been estimated that approximately $90 \%$ of drowning in this age group takes place in these swimming pools. 44

Rimsza et al. found out that most drowning children are younger than five years; $61 \%$ of these deaths occurred in private swimming pools. They consider that the greatest drowning risk is posed by a backyard swimming pool when young boys are not being supervised by an adult. ${ }^{38}$

The risk of death in cases of submersion is quite high; thus, preventive guidance for parents or surrogates must include information about the risks of drowning in bathtubs and residential swimming pools. ${ }^{37}$

Based on the recommendations made by Cody et al., parents should pay attention to four aspects regarding child safety: supervision, environment, equipment and education. 62

Supervision: it is imperative that there be an adult to watch over young children while they remain in the water or are next to it, and no children should be allowed to swim if not supervised by an adult. The supervisor is not supposed to do anything else but supervise the child all the time. He/ she must remain close to the child so that he/she can take an immediate and safe action, if necessary. The supervisor is not supposed to carry out other activities that may divert his/her attention, such as cooking, reading or making a phone call. If the child cannot swim, the supervisor must be close to the child all the time, so as to be able to take the child in his/her arms if necessary. ${ }^{62}$

Environment: swimming must be practiced in an appropriate place and be supervised. The four corners of the swimming pool and water tanks should be at least 1.5 $\mathrm{m}$ in height; the gate should close automatically and the latch must be automatic, too. Besides a fence, the swimming pool must have a roof and have an alarm system on the door or lock. Precaution with residential water tanks should be taken so as to prevent children from having access to them, by installing door locks and toilet latches. Portable swimming pools and buckets must be emptied immediately after use. 62

Equipment: children must wear appropriate safety equipment. 62

Education: children should learn how to swim and be instructed about safety precautions that should be followed while in the water. ${ }^{62}$

\section{Safety in the rural environment}

When studying patients between 0 and 19 years old, who had been hospitalized due to external causes of morbidity and mortality, Gaspar found out that $14.1 \%$ lived in the countryside. ${ }^{41}$

Pickett et al. observed that a large number of injuries that occur on farms to the children and adolescents who live there or spend a holiday there, are not work-related. The authors cite five important measures that may help prevent these injuries: 63

1. Children should not be allowed where adults are working, since in this case, children cannot be properly supervised.

2. There should be barriers to prevent children from accessing places that may pose any risks (passive protection).

3. Put away, safely, farm tools and equipment, not allowing children to have access to the places where they are stored.

4. Develop ways to look after children in a safe manner, preventing them from getting to the places where adults work. 
5. Establish rules for leisure activities in the rural environment. 63

\section{Snakebites}

Snakebites are extremely dangerous; nearly $90.5 \%$ are caused by Bothrops snakes. Males are more commonly bitten than females. Usually, bites are on the feet and legs, and on hands and forearms. Prompt treatment is crucial for a better prognosis. ${ }^{64}$ They often occur in individuals who live predominantly in the countryside. ${ }^{41}$

The following preventive measures, based on the Manual for the Diagnosis and Treatment of Venomous Bites, are recommended: 64

1. The best preventive measure is to wear knee-length boots or leather pants with ankle-length boots or shoes.

2. Leather gloves should be worn to prevent bites on the hands and forearms while handling piles of garbage, dry leaves and straw. One should never put one's hands into dark places, such as rock crevices or hollow logs.

3. Snakes usually hide in dark, hot and damp places. Thus, caution should be exercised when working on or around places with these characteristics, such as piles of firewood and sugarcane, beans and corn stubble.

4. Rats indicate the presence of snakes. It is necessary to keep the dooryard and storage facilities always clean. Holes on walls and doors must be plugged.

5. Clean around the house, avoid accumulation of rubble, garbage, wood, rocks, tiles and bricks, which contribute to the presence of small animals snakes feed on. Keep the lawn cut low and clean.

\section{Scorpion envenomation}

Scorpion stings are life-threatening, especially in children, and if the sting is from a Tityus serrulatus. Stings are often on the hands and forearms. ${ }^{64}$ Most of them occur at home ${ }^{46}$ and over $50 \%$ in the countryside. ${ }^{41}$

In Brazil, approximately $50 \%$ of notified scorpion envenomations occur in the states of Minas Gerais and São Paulo. 64

The following preventive measures, based on the Manual for the Diagnosis and Treatment of Venomous Bites, are recommended: 64

1. Clean around the house. Neighboring vacant lots should also be cleaned. Avoid accumulation of rubble, dry leaves, garbage, woods, rocks, tiles and bricks.

2. Mow the lawn regularly. Avoid contact with banana trees, climbing plants and other types of thick vegetation near walls.

3. Carefully look inside clothes and shoes and shake them before putting them on. Do not hang clothes to dry in contact with walls.

4. Cover the door sill and close the windows at sundown. Install screens on the drains of floors, sinks, and laundry tubs. Plug holes on the walls, floor and other places through which scorpions may crawl into the house.
5. Place beds and cribs away from the wall. Blankets, sheets and mosquito nets should never be left hanging down to touch the floor.

6. Place domestic garbage in plastic bags or in hermetically sealed containers to avoid attracting insects (cockroaches, flies, etc.), which serve as food for scorpions.

7. Do not kill night fowls, hens, geese, lizards and frogs, because they naturally feed on scorpions.

\section{Counseling measures, the role of the government, of civil society and of prevention campaigns}

Passive interventions are the most efficient measures to prevent injuries. These interventions do not depend on the exposed individual's volition to protect himself/herself. Examples of passive intervention measures include bars on windows, smoke detectors, automatic sprinklers and childproof caps on prescription bottles, which have been used in the USA for over two decades. ${ }^{65}$ Others, such as the combination of laws and control of events and government intervention in the regulation of measures have also proved efficient for several years. 66

Pickett et al. believe that parents and caregivers are the ones who should be in charge of preventing injuries to their infants; therefore, they should be able to recognize the possible occurrence of events beforehand and implement preventive measures. ${ }^{53}$ The study on injury prevention recommends initiatives that can be summarized into anticipation, action and responsibility. Pickett et al. noted that all the analyzed cases could have been prevented if the possibility of injury had been foreseen by the parent/ surrogate, and if that person had taken some action to prevent the injury. The injury patterns described in the study are recurrent, for that reason, it is important that preventive measures be based on evidence.

The importance of reliable supervision of children aged between 0 and 6 years was shown by Landen et al. who, after analyzing the deaths caused by injuries in this age group, concluded that $43 \%$ of them could have been prevented as they occurred due to improper supervision. 67 Thus, one of the strategies for the prevention of these deaths is to improve supervision of children.

Three aspects are regarded as essential for a good supervision: attention to the child and to the environment, physical and emotional proximity and continuity of the supervision. The specific aspects of this supervision must include family and community characteristics, as well as political ones and regulation aspects to be established for active and passive prevention of injuries. ${ }^{68}$

Pediatricians should instruct parents on how to prevent environmental risks, since their advice may be extremely beneficial to children's health. ${ }^{44}$ Therefore, the perception of risk and subsequent injury prevention measures (either active or passive) will be influenced by the characteristics of the social context in which children are inserted. It includes both family structure (family size, number of children, maternal age) and regulatory policies (traffic laws or drug 
control policies). Still within this context, the use of these policies will influence the perception and implementation of active and passive preventive measures by parents or surrogates. Therefore, the cultural and social context is closely related to the dynamics of risk perception, which is also defined by the characteristics of the caregiver, of the child and of the environment.

Studies carried out in the last decade indicated potential preventive measures, ${ }^{69}$ even if scant evidence exists regarding the reduction of injuries by means of campaigns and donation of protective equipment. ${ }^{70-73}$ The approaches that underscore the necessity of an active role of parents and surrogates reduced injuries moderately. ${ }^{74}$ With less intervention capacity, exclusively explanatory and instructive measures usually do not yield effective results. ${ }^{75}$

There is insufficient evidence to determine the effects of environmental changes on the reduction of risks. The studies focusing on environmental intervention were not successful in showing conclusive results on its power of intervention, especially because they used previous occurrence of accidents as a parameter. ${ }^{76}$ Developing communities have difficulty encouraging protective actions against injuries, but there is no established correlation between the different characteristics of municipalities and their capacity to develop physical protection. ${ }^{77}$

\section{Conclusions}

It is essential that health professionals understand the importance of injury prevention. Predominantly still defined as accident nowadays, injury must be dealt with through control measures and scientifically efficient approaches; otherwise, there will be no benefits to children's health.

Because of the effects on morbidity and mortality, this group of injuries is the one with the highest economic impact over a country, in addition to its overwhelming effect on families.

However, if we can act in a systematic way by extending actions beyond the health sector using an intersectoral approach, we will be actually able to reverse the situation. A set of initiatives can be developed by each community and by each health service.

The management of unintentional physical injuries is under the responsibility of pediatricians, but it is an initiative everyone can take part in.

\section{References}

1. Ministério da Saúde. Morbidade hospitalar do SUS por causas externas - por local de residência - Brasil 2004. http:// tabnet.datasus.gov.br/cgi/tabcgi.exe?sih/cnv/eruf.def. Acesso: 20/04/2005.

2. Ministério da Saúde. Mortalidade. Óbitos por residência por faixa etária determinada segundo Capítulo CID-10 - Causas externas de morbidade e mortalidade - Brasil 2002. http:// tabnet.datasus.gov.br/cgi/tabcgi.exe?sim/cnv/obtuf.def. Acesso: 04/04/2005
3. Anderson RN, Smith BL. Deaths: leading causes for 2001. National Vital Statistics Reports; vol. 52 no 9. Hyattsville, Maryland: National Center for Health Statistics, 2003.

4. Angus DE, Cloutier E, Albert T, Chenard D, Shariatmadar A, Pickett $W$, et al. The economic burden of unintentional injury in Canada. Toronto: Smartrisk; 1998.

5. Zhao Z, Svanström L. Injury status and perspectives on developing community safety promotion in China. Health Promot Int. 2003;18:247-53.

6. Valent F, Little D, Tamburlini G, Barbone F. Burden of disease attributable to selected environmental factors and injuries among Europe's children and adolescents. Geneva, World Health Organization, 2004 (WHO Environmental Burden of Disease Series, no 8).

7. Ballesteros MF, Schieber RA, Gilchrist J, Holmgreen P, Annest JL. Differential ranking of causes of fatal versus non-fatal injuries among US children. Inj Prev. 2003;9:173-6.

8. Flinders University Adelaide, Australia. Research Centre for Injury Studies. Estimated cost of injury by all causes. Australia 1995-96. www.nisu.flinders.edu.au/pubs/injcost/allcause.html. Acesso: 10/03/2005.

9. Centers for Disease Control and Prevention. Medical expenditures attributable to injuries in the U.S., 2000. MMWR. 2004;53:1-4.

10. Centers for Disease Control and Prevention. National Center for Health Statistics. National hospital discharge survey, public use data. 2001. www.cdc.gov/nchs/fastats/acc-inj.htm. Acesso: 19/04/2005.

11. McCaig LF, Burt CW. National Hospital Ambulatory Medical Care Survey: 2003 emergency department summary. Advance data from vital and health statistics; no 358 . Hyattsville, Maryland: National Center for Health Statistics, 2005. http://198.246.96.2/ nchs/data/ad/ad358.pdf.

12. Thanh NX, Hang HM, Chuc NT, Lindholm L. The economic burden of unintentional injuries: a community-based cost analysis in Bavi, Vietnam. Scand J Public Health. 2003;31(Suppl. 62):45-51.

13. Centers for Disease Control and Prevention. Years of potential life lost before age 65-United States, 1990 and 1991. MMWR 1993;42:251-3.

14. National Committee for Injury Prevention and Control. Injury prevention: meeting the challenge. New York: Oxford University Press, 1989.

15. National Safety Council. Injury facts, 2001. Itasca (IL): National Safety Council; 2001.

16. Kopjar B, Wickizer T. Population-based study of unintentional injuries in the home. Am J Epidemiol. 1996;144:456-62.

17. Ballesteros, MF, Schieber RA, Gilchrist J, Holmgreen P, Annest JL. Differential ranking of causes of fatal versus non-fatal injuries among US children. Inj Prev. 2003;9:173-6.

18. Runyan C, Perkis D, Marshall S., Johnson R, Coyne-Beasley T, Waller $A$, et al. Unintentional injuries in the home in the United States Part II: Morbidity. Am J Prev Med. 2005;28:80-7.

19. Maciel W, Paes CE. Riscos no ambiente doméstico e em áreas de lazer. In: Campos JA, Paes CE, Blank D, Costa DM, Pfeiffer L, Waksman RD. Manual de Segurança da Criança e do Adolescente. Sociedade Brasileira de Pediatria/Nestlé Nutrição, 2004. p. 65-74.

20. Waisman I, Núñez JM, Sánchez J. Epidemiología de los accidentes en la infancia en la Región Centro Cuyo. Rev Chil Pediatr. 2002;73:404-14

21. Ministério da Saúde. Morbidade hospitalar do SUS por causas externas - por local de internação - Brasil 2004. Internações por faixa etária 1 segundo grupo de causas. http:// tabnet.datasus.gov.br/cgi/tabcgi.exe?sih/cnv/eiuf.def. Acesso: 05/05/2005.

22. Public Health Agency of Canada. For The Safety of Canadian Children and Youth: From Injury Data to Preventive Measures. Ottawa, 1997.

23. National Center for Health Statistics. National Vital Statistics System (NVSS) data, 1992-1999, ICPSR version. Atlanta GA: Centers for Disease Control and Prevention; Ann Arbor MI: Inter-University Consortium for Political and Social Research, University of Michigan (distributor). www.icpsr.umich.edu/ index.html. Acesso: 10/05/2005.

24. Phelan KJ, Khoury J, Kalkwarf H, Lanphear B. Residential injuries in U.S. children and adolescents. Public Health Rep. 2005;120:63-70. 
25. Hambidge SJ, Davidson AJ, Gonzales R, Steiner JF. Epidemiology of pediatric injury-related primary care office visits in the United States. Pediatrics. 2002;109:559-65.

26. Gaspar VLV, Lamounier JA, Cunha FM, Gaspar JC. Fatores relacionados a hospitalizações por injúrias em crianças e adolescentes. J Pediatr (Rio J). 2004;80:447-52.

27. Plitponkarnpim A, Andersson R, Jansson B, Svanstrom L. Unintentional injury mortality in children: a priority for middle income countries in the advanced stage of epidemiological transition. Inj Prev. 1999;5:98-103.

28. Zwi AB, Leon D, Koupilova I, Sethi D, McKee M. Injuries, inequalities and health in Europe. Inj Control Saf Promot. 2001;8:143-8.

29. Zhao Y, Guthridge S, Magnus A, Vos T. Burden of disease and injury in Aboriginal and non-Aboriginal populations in the Northern Territory. MJA. 2004;180:498-502.

30. Laflamme L. Explaining socio-economic differences in injury risks. Inj Control Saf Promot. 2001;8:149-53.

31. Wadsworth J, Burnell I, Taylor B, Butler N. Family type and accidents in preschool children J Epidemiol Community Health. 1983;37:100-4.

32. Moore R, Ormandy D. Home safety in the UK: review of the influence of human and housing factors. Rev Environ Health. 2004;19:253-70.

33. Bremberg S. Does an increase of low income families affect child health inequalities? A Swedish case study. J Epidemiol Community Health. 2003;57:584-8.

34. Engstrom K, Diderichse F, Laflamme L. Socioeconomic differences in injury risks in childhood and adolescence: a nation-wide study of intentional and unintentional injuries in Sweden. Inj Prev. 2002; $8: 137-42$.

35. Fonseca SS, Victora CG, Halpern R, Barros AJ, Lima RC, Monteiro LA, et al. Fatores de risco para injúrias acidentais em pré-escolares. J Pediatr (Rio J). 2002;78:97-104.

36. Kendrick D, Watson M, Mulvaney C, Burton P. How useful are home safety behaviours for predicting childhood injury? A cohort study. Health Educ Res. Access published on March 8, 2005, DOI 10.1093/her/cyh021.

37. Agran PF, Anderson C, Winn D, Trent R, Walton-Haynes L, Thayer S. Rates of pediatric injuries by 3 -month intervals for children 0 to 3 years of age. Pediatrics. 2003;111:683-92.

38. Rimsza ME, Schackner RA, Bowen KA, Marshall W. Can child deaths be prevented? The Arizona child fatality review program experience. Pediatrics. 2002 Jul;110(1). www.pediatrics.org/ cgi/content/full/110/1/e11. Acesso: 20/11/2003.

39. Rubin DM, Christian CW, Bilaniuk LT, Zazyczny KA, Durbin DR. Occult head injury in high-risk abused children. Pediatrics. 2003; 111:1382-6.

40. Dias MS, Smith K, deGuehery K, Mazur P, Li V, Shaffer ML. Preventing abusive head trauma among infants and young children: a hospital-based, parent education program. Pediatrics. 2005;115:470-7.

41. Gaspar VL Hospitalização por acidentes em crianças e adolescentes, em Ipatinga, Minas Gerais [dissertação]. Belo Horizonte (MG): Faculdade de Medicina da Universidade Federal de Minas Gerais; 2002.

42. Mukerji G, Chamania S, Patidar GP, Gupta S. Epidemiology of paediatric burns in Indore, India. Burns. 2001;27:33-8.

43. Delgado J, Ramírez-Cardich ME, Gilman RH, Lavarello R, Dahodwala N, Bazán A, et al. Risk factors for burns in children: crowding, poverty, and poor maternal education. Inj Prev. 2002;8:38-41.

44. Brent RL, Weitzman M. The pediatrician's role and responsibility in educating parents about environmental risks. Pediatrics. 2004;113:1167-72.

45. Rangel AM, Hernández MF, Herrera ER, Martínez LA. Morbilidad por intoxicaciones agudas en el Hospital Pediátrico de Cienfuegos durante el quinquenio 1996-2000. Rev Cubana Pediatr. 2004; 76. http://bvs.sld.cu/revistas/ped/vol76_3_04/ped07304.htm. Acesso: 25/02/2005.

46. Amorim AM, Carvalho FM, Lira-da-Silva RM, Brazil TK. Acidentes por escorpião em uma área do Nordeste de Amaralina, Salvador, Bahia, Brasil. Rev Soc Bras Med Trop. 2003;36:51-6.

47. Çekin N, Hilal A, Gülmen MK, Kar H, Aslan M, Özdemir H. Medicolegal childhood deaths in Adana, Turkey. Tohoku J Exp Med. 2005;206:73-80.

48. Peden M, McGee K, Krug E, editors. Injury: a leading cause of the global burden of diseases, 2000. Geneva: World Health Organization; 2002
49. Britton JW. Kids can't fly: preventing fall injuries in children. WMJ. 2005;104:33-6.

50. Sandi KP, Salas HM. Factores de riesgo para accidentes en niños. Arch Pediatr Urug. 2005;76:65-74.

51. Dedoukou X, Spyridopoulos T, Kedikoglou S, Alexe DM, Dessypris $\mathrm{N}$, Petridou $\mathrm{E}$. Incidence and risk factors of fall injuries among infants. Arch Pediatr Adolesc Med. 2004;158:1002-6.

52. Stone KE, Lanphear BP, Pomerantz WJ, Khoury J. Childhood injuries and deaths due to falls from windows. J Urban Health. $2000 ; 77: 26-33$.

53. Pickett W, Streight S, Simpson K, Brison RJ. Injuries experienced by infant children: a population-based epidemiological analysis. Pediatrics. 2003;111:365-70.

54. Macgregor DM. Injuries associated with falls from beds. Inj Prev. 2000;6:291-2

55. Macarthur C. Evaluation of safe kids week 2001: prevention of scald and burn injuries in young children. Inj Prev. 2003;9:112-6.

56. Hall E, Saxe G, Stoddard F, Kaplow J, Koenen K, Chawla N, et al. Posttraumatic stress symptoms in parents of children with acute burns. J Pediatric Psychol. 2005;77:26-33.

57. Drago DA. Kitchen scalds and thermal burns in children five years and younger. Pediatrics. 2005;115:10-6.

58. Runyan C, Bangdiwala S, Linzer M, Sacks J, Butess J. Risk factors for fatal residential fires. N Engl J Med. 1992;327:859-63.

59. Lam LT. Childhood and adolescence poisoning in NSW, Australia: an analysis of age, sex, geographic, and poison types. Inj Prev. 2003; 9:338-42.

60. Agran PF, Winn D, Anderson C, Trent R, Walton-Haynes L. Rates of pediatric and adolescent injuries by year of age. Pediatrics. 2001 Sep;108(3). www.pediatrics.org/cgi/content/full/108/3/ e45. Acesso: 20/11/2001.

61. American Academy of Pediatrics. Poison treatment in the home. Pediatrics. 2003;112:1182-5.

62. Cody BE, Quraishi AY, Dastur MC, Mickalide AD. Clear danger: A national study of childhood drowning and related attitudes and behaviors. Washington (DC): National Safe Kids Campaign, April 2004.

63. Pickett W, Brison RJ, Berg RL, Zentner J, Linneman J, Marlenga B. Pediatric farm injuries involving non-working children injured by a farm work hazard: five priorities for primary prevention. Inj Prev. 2005;11:6-11.

64. Ministério da Saúde. Manual de diagnóstico e tratamento de acidentes por animais peçonhentos. $2^{a}$ ed. Brasília: Fundação Nacional de Saúde; 2001.

65. Centers for Disease Control. Childhood injuries in the United States. Am J Dis Child. 1990;144:627-46.

66. Spiegel CN, Lindaman FC. Children can't fly: a program to prevent childhood morbidity and mortality from window falls. Am J Public Health. 1977;67:1143-7.

67. Landen MG, Bauer $U$, Kohn $M$. Inadequate supervision as a cause of injury deaths among young children in Alaska and Louisiana. Pediatrics. 2003;111:328-31.

68. Saluja G, Brenner R, Morrongiello B, Haynie D, Rivera M, Cheng TL. Injury Control \& Safety Promotion. 2004;11:17-22.

69. Sznajder $M$, Leduc $S$, Janvrin MP, Bonnin $M H$, Aegerter $P$, Baudier $F$, et al. Home delivery of an injury prevention kit for children in four French cities: a controlled randomized trial. Inj Prev. 2003;9:261-5.

70. King WJ, Klassen TP, LeBlanc J, Bernard-Bonnin AC, Robitaille Y, Pham $B$, et al. The effectiveness of a home visit to prevent childhood injury. Pediatrics. 2001;108:382-8.

71. Spinks A, Turner C, McClure R, Nixon J. Community based prevention programs targeting all injuries for children. Inj Prev. 2004; 10:180-5.

72. Nixon J, Spinks A, Turner C, McClure R. Community based programs to prevent poisoning in children 0-15 years. Inj Prev. 2004; 10:43-6.

73. Watson M, Kendrick D, Coupland C, Woods A, Futers D, Robinson J. Providing child safety equipment to prevent injuries: randomised controlled trial. BMJ. 2005;330:178-81.

74. King WJ, LeBlanc JC, Barrowman NJ, Klassen TP, BernardBonnin A-C, Robitaille $Y$, et al. Long term effects of a home visit to prevent childhood injury: three year follow up of a randomized trial. Inj Prev. 2005;11:106-9.

75. Gielen AC, McDonald EM, Wilson ME, Hwang W-T, Serwint JR, Andrews JS, et al. Effects of improved access to safety counseling, products, and home visits on parents' safety practices. Arch Pediatr Adolesc Med. 2002;156:33-40. 
76. Lyons RA, Sander LV, Weightman AL, Patterson J, Jones SA, Lannon S, et al. Modification of the home environment for the reduction of injuries. The Cochrane Database of Systematic Reviews 2003, Issue 4. www.cochrane.org/cochrane/revabstr/ AB003600.htm.

77. Guldbrandsson K, Bremberg S. A study of safety-promoting activities for children and adolescents in 25 Swedish municipalities. Health Promot Int. 2004;19215-26.
Correspondence:

Carlos Eduardo Nery Paes

Rua Francisco Ferrer, 273/601, Rio Branco

CEP 90420-140 - Porto Alegre, RS, Brazil

E-mail: paes@superig.com.br 